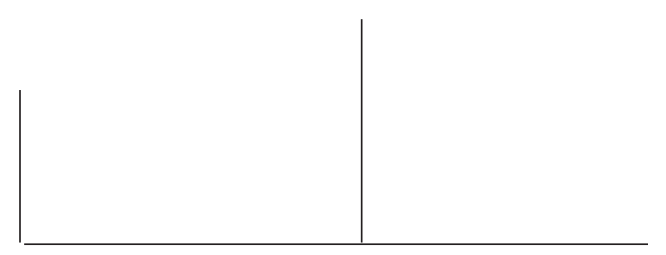

Rev. Latinoam. Psicopat. Fund., V, 3, 124-137

\title{
A capacidade do bebê para estar só e o isolamento autista
}

Maria Izabel Tafuri

O tratamento preventivo das perturbações precoces com o risco de evolução Autista é discutido nesse texto como uma ação paradoxal do ponto de vista psicanalítico. A prevenção implica na perpetuação do pensamento psiquiátrico kraepeliano sobre a evolução obrigatória de um conjunto de sintomas de uma referida doença. Ao mesmo tempo enfatiza-se a necessidade do tratamento precoce de bebês com isolamento patológico.

Palavras-chave: Autismo, auto-erotismo, prevenção, psicopatologia, páthos 
O interesse científico em detectar e tratar precocemente o isolamento patológico no bebê surgiu a partir da gravidade de quadros psicopatológicos da infância que alteram de forma invasiva o desenvolvimento global do ser humano. Nessa linha a síndrome do Autismo infantil precoce, descrita por Léo Kanner, em 1943, influenciou o pensamento médico psiquiátrico a respeito da necessidade de se tratar precocemente crianças isoladas que não desenvolvem contato afetivo com as pessoas.

Se até a década de 1990 o isolamento autista só era observado e tratado a partir dos três anos de idade, atualmente, existem escalas diagnósticas para detectar precocemente o bebê isolado e desinteressado pelo meio externo. Essa possibilidade de diagnosticar precocemente o Autismo infantil precoce, ou de determinar as perturbações precoces com o risco de evolução autista, traz implícito o modelo médico clássico: a evolução necessária dos sintomas de uma referida doença. Essa situação coloca o psicanalista em um lugar polêmico pois o tratamento do bebê, se qualificado de preventivo, deixa de ser individualizado e passa a ser marcado por uma sintomatologia que evolui segundo leis determinadas a priori.

As manifestações mais precoces da síndrome do Autismo infantil precoce podem ser pesquisadas por meio de dois 


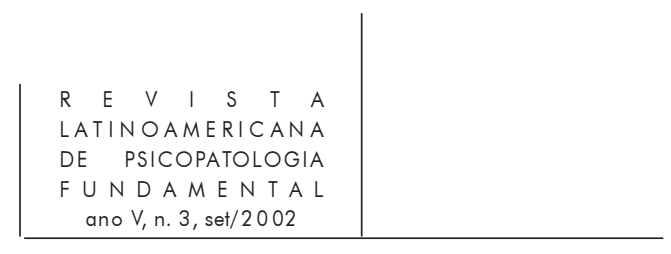

eixos básicos metodológicos. O primeiro eixo compreende a observação direta do comportamento do bebê, e, o segundo, as hipóteses re-construtivas, realizadas a posteriori, a partir da história de vida da criança. Uma história que pode ser analisada por meio da anamnese médica/psicológica, onde os pais relatam as fases do desenvolvimento da criança, mostram vídeos, retratos, etc. Ou ainda ser analisada a partir do discurso dos pais sobre eles mesmos e a criança, na relação transferencial com o psicanalista.

No primeiro eixo de pesquisa, os padrões comportamentais que indicam o isolamento patológico na vida da criança são descritos desde os primeiros dias de vida do bebê. Como pode ser visto na Classificação Diagnóstica de Saúde Mental e Transtornos do Desenvolvimento do Bebê e da Criança Pequena: 0-3, “... os padrões comportamentais de crianças absortas em si mesmas incluem criatividade e imaginação, combinadas com uma tendência da criança a sintonizarse em suas próprias sensações, pensamentos e emoções, em vez de sintonizar e prestar atenção às comunicações de outras pessoas. Os bebês podem parecer absortos em si mesmos, tornando-se interessados em objetos, mais através de exploração solitária do que no contexto da interação" (1997, p. 37). Essa descrição comportamental é classificada no Eixo I: diagnóstico primário, como Transtornos Regulatórios do Tipo II: Hiporreativo (402).

Nota-se que nessa descrição classificatória é estabelecida uma relação linear causal entre dois padrões comportamentais: "a tendência em estar absorto consigo mesmo" e "o desinteresse às comunicações das pessoas". Trata-se de uma conclusão no mínimo discutível. Se, por um lado, os padrões comportamentais descritos com relação aos bebês são da ordem do observável, o mesmo não se pode dizer da relação linear causal entre esses dois padrões comportamentais. A causalidade linear é atribuída pelo observador, pois, na verdade, o que é observável são os dois padrões comportamentais que podem ocorrer ao mesmo tempo ou em diferentes momentos. Por que estabelecer uma relação linear causal entre eles? Por que "estar sintonizado em suas próprias sensações e/ou fantasias" é considerado um comportamento que impede o bebê ou a criança pequena de prestar atenção às comunicações de outras pessoas?

O questionamento da relação linear causal entre os dois padrões comportamentais - "estar absorto consigo mesmo" e "estar desinteressado às comunicações das pessoas" - possibilita pensar sob um outro prisma, a saber, o papel da criatividade e da imaginação do bebê nesses comportamentos. Quais as relações existentes entre "estar absorto consigo mesmo" e a capacidade do bebê e da criança pequena de "criar, imaginar e fantasiar"?

O estudo das psicopatologias precoces relacionadas ao desenvolvimento da criança evidencia um ponto central da discussão sobre a relação linear causal entre "estar absorto consigo mesmo" e a "capacidade de criar, imaginar e fantasiar". 


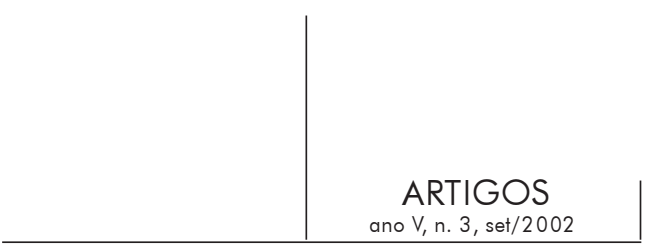

À luz da importante obra de Bleuler (1911) sobre as Esquizofrenias, Potter (1933) descreveu um novo quadro psicopatológico, a Esquizofrenia infantil. Segundo Potter, as crianças, assim como os adultos, rompem repentinamente o contato com a realidade, depois de um período de desenvolvimento normal, e preservam uma vida interior fantasiosa e criativa, porém privada e isolada. A predominância mórbida de uma vida interior preenchida por pensamentos criativos e fantasiosos havia sido definida anteriormente por Bleuler como um dos sintomas secundários mais importantes do quadro das Esquizofenias. Na realidade, desde Bleuler, o pensamento criativo dos esquizofrênicos havia recebido a denominação médica de pensamento autístico, tanto no caso dos adultos quanto das crianças.

Com os trabalhos posteriores de Lutz (1937), Bender (1938), Bradley (1939) e, em especial, de Léo Kanner - autor da síndrome do Autismo infantil precoce - a noção de autismo na vida infantil ganhou uma outra significação. Kanner, em particular, estabeleceu uma distinção importante entre a Esquizofrenia infantil e o Autismo infantil precoce. Segundo ele, na Esquizofrenia infantil, o rompimento com a realidade ocorre de forma insidiosa depois do terceiro ano de vida, e é acompanhado de pensamentos autísticos.

Com as descrições psicopatológicas trazidas por Lutz, Bender, Bradley, Kanner e outros, estabeleceu-se no meio científico uma relação linear causal simplista entre "rompimento da realidade" e "pensamento autístico". Essa simplificação é bem radical quando comparada à descrição original das Esquizofrenias por Bleuler, onde essa relação é muito mais complexa e envolve uma compreensão mais ampla sobre o "sujeito falante".

Bleuler, influenciado pela obra de Freud (1910) sobre A interpretação dos sonhos, chamou a atenção da comunidade médica para o pensamento autístico do esquizofrênico. Seu objetivo foi o de demonstrar que o médico poderia dar sentido à fala aparentemente ilógica do esquizofrênico desde que ouvisse com atenção o paciente, e não apenas o medicasse, ou o desconsiderasse enquanto "ser falante". Nesse sentido, Bleuler promoveu uma transformação inovadora da análise psicopatológica das grandes psicoses e, juntamente com Jung, seu assistente, aplicou, pela primeira vez, as idéias freudianas à investigação clínica da loucura. Bleuler passou a analisar seus pacientes por meio de uma análise retrospectiva contada pelo "sujeito falante" e, assim, rompeu com o modelo clássico psiquiátrico.

Em síntese, a relação entre "isolamento da realidade" e "pensamento autístico" foi inicialmente tratada por Bleuler, no contexto da psiquiatria, de forma mais ampla e complexa do que aquela presente na Classificação Diagnóstica: 0 a 3. E a influência da obra de Kanner sobre o Autismo infantil precoce pode ser apontada como um fator decisivo para a descrição de uma causalidade linear entre "isolamento" e "autismo". 


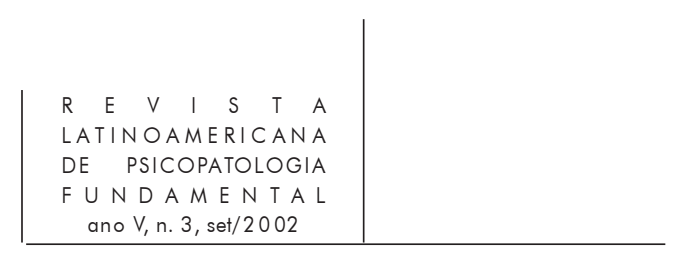

Kanner (1943) postulou que a criança autista não estabelece contato com a realidade desde o início da vida, e não apresenta pensamentos fantasiosos. Kanner (1956) também remarcou que o termo "rompimento com a realidade" (spaltung/ withdrawal), utilizado por Bleuler para definir o sintoma primário das Esquizofrenias, não seria adequado para descrever o que ocorre no autismo.

Ao distinguir o Autismo infantil precoce do grupo das Esquizofrenias, Kanner (1955) criou um paradoxo. Ele transformou o adjetivo "autístico" em um substantivo "autismo" e o usou para nomear a síndrome por ele descrita - "o isolamento da criança autista não é autístico" - (Tafuri, tese de doutorado, inédita). Ou seja, para Kanner, o isolamento da criança autista não é acompanhado de pensamentos criativos, imaginários e fantasiosos. Portanto, a criança autista não apresenta pensamentos autísticos. Trata-se, segundo o autor, de um isolamento profundo, impenetrável e inacessível, não acompanhado de pensamentos autísticos, presente na vida da criança desde o seu nascimento.

Se, antes de Kanner, o adjetivo autístico servia para descrever em linguagem médica o pensamento fantasioso e criativo do esquizofrênico, posteriormente à sua obra, o substantivo autismo passou a descrever "a incapacidade neurobiológica da criança de estabelecer contato com o meio externo". Mais ainda, o termo autismo passou a ser signo de um déficit neurobiológico inato, inscrito, inclusive, na classificação das doenças mentais (OMS, 1975; CID-10, 1990; DSM-III-R, 1989; DSM-IV). A constatação dessa mudança de percepção é de suma importância para investigar corretamente os sinais de isolamento patológico no bebê. Permite também questionar a tendência atual e generalizada de diagnosticar sinais de isolamento patológico no bebê como isolamento autista.

Vale a pena enfatizar que as descrições de Kanner dizem respeito ao isolamento de crianças autistas de mais de dois anos de idade, e não ao isolamento inato de bebês que, posterior e eventualmente, se tornam autistas quando crianças. $\mathrm{O}$ estudo de Kanner foi retrospectivo, realizado por meio das anamneses feitas com os pais das crianças autistas observadas. Dessa forma, Kanner chegou aos índices patológicos no desenvolvimento daquelas crianças e estabeleceu uma relação linear causal entre os índices encontrados com o quadro clínico da síndrome.

Atualmente, os pesquisadores investigam filmes das crianças diagnosticadas de autistas, realizados pelos familiares das crianças, e estabelecem índices patológicos precoces de isolamento autista. E assim ficou estabelecido no meio científico uma relação de similaridade entre o isolamento autista de uma criança de três anos de idade com o isolamento patológico de um bebê, a exemplo da classificação do Espectro Autista para o bebê, descrita na Classificação Diagnóstica: 0 a 3. Esses índices patológicos estão relacionados a tipos de isolamento que surgiram no desenvolvimento de crianças já diagnosticadas de 


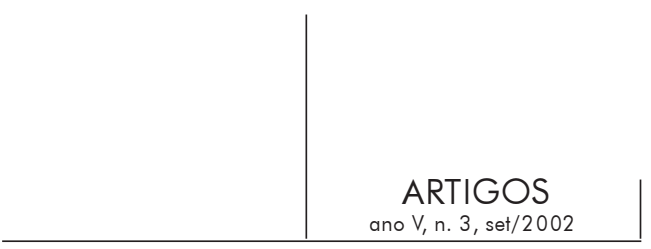

autistas a partir dos dois anos de idade. Ao denominarem os índices patológicos de isolamento como isolamento autista, os cientistas modernos, à moda de Kanner, instauraram uma problemática. Por que denominar de autista o isolamento patológico de um bebê?

A resposta a essa indagação na linha psiquiátrica pós-Kanner são os dos dados científicos obtidos por meio das pesquisas retrospectivas sobre o desenvolvimento das crianças diagnosticadas de autistas a partir dos dois anos de idade. Em 1943, por exemplo, Kanner determinou que a ausência do comportamento antecipatório do bebê ${ }^{1}$ é um índice patológico do Autismo infantil precoce porque todas as crianças autistas observadas por ele apresentaram esse déficit:

... todas as crianças de nosso grupo mostraram, desde o começo da vida, um fechamento extremo, não reagindo a nada do que proviesse do mundo exterior. Isto é expresso de forma mais característica pelo relato constantemente feito do fracasso da criança em adotar uma atitude antecipatória antes de ser carregada e em ajustar a posição de seu corpo ao da pessoa que a segura nos braços. (Kanner, 1943, p. 41)

Ainda segundo essa Classificação Diagnóstica, um bebê está dentro do espectro autista (Transtorno do Relacionamento e Comunicação. Eixo I: 700; Classificação Diagnóstica: 0 a 3 ) quando apresenta os seguintes comportamentos: absorto consigo mesmo, desinteressado às comunicações de outras pessoas, envolvido em atividades sensoriais repetitivas com uma limitação de idéias e fantasias nas brincadeiras. Nota-se que essa descrição comportamental é similar àquela descrita desde Kanner até as várias edições do Manual Diagnóstico Estatístico das Doenças Mentais, DSM-III-R e o DSM-IV, que afirmam o autismo como um fracasso em desenvolver relacionamentos interpessoais e pela falta de responsividade a, ou interesse pelas pessoas; uma falha em aconchegar-se, pela falta de contato visual e responsividade facial, e por indiferença ou aversão a afeto e contato físico.

Observa-se que a descrição comportamental do autismo no bebê é similar à do autismo na criança o que coloca o clínico em uma posição complexa. É como formar um quebra-cabeça já se sabendo a priori a figura final a ser formada: os índices patológicos de isolamento autista são as peças marcadas desse quebracabeça, definidas a priori como sintomas que poderão evoluir para a instalação do Autismo infantil precoce. Essa posição é contraditória levando-se em conta o

1. Kanner se referiu ao trabalho de Gesell, "uma criança de 4 meses adota uma atitude antecipatória inclinando o rosto e mexendo os ombros, quando levantada ou colocada sobre uma mesa" (1943, p. 33). Para Gesell, essa experiência humana é universal e a resposta do bebê é suficientemente objetiva para merecer uma ampla observação. 


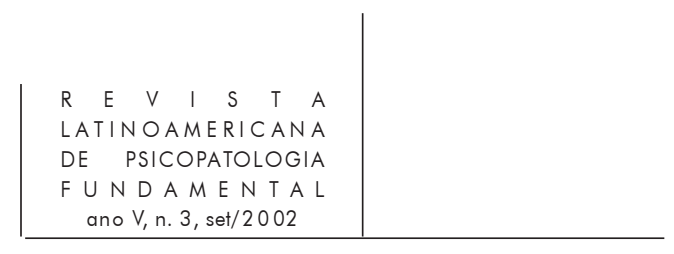

saber científico atual sobre as capacidades psiconeurobiológicas do bebê, como também o princípio psicanalítico básico que o bebê é um ser único marcado por sua história individual. Nesse sentido, cabe ao clínico montar um quebra-cabeça junto a seu paciente sem o conhecimento predeterminado sobre a figura final a ser formada. E se algumas peças estiverem "doentes" e não se ajustarem umas às outras para formar uma figura maior, não determinada a priori, surge a necessidade de um tratamento precoce. Precoce no sentido de permitir um encaixe entre as peças para que o processo de constituição da figura final não fique estancado. $\mathrm{O}$ tratamento precoce, no caso, não tem o sentido de prevenir a constituição de uma figura já conhecida a priori.

Pensando dessa forma, os sinais de indiferença do bebê podem indicar um isolamento, mas não necessariamente um isolamento autista. Qualificar o isolamento de um bebê como autista é o mesmo que determinar, a priori, a evolução necessária dos sintomas de uma referida doença. Não se trata de pensar em prevenção da doença do Autismo infantil precoce, pois esse pensamento recai no paradoxo de Kanner, sobre o isolamento inato autista. Diferentemente do paradoxo kanneriano, é necessário vislumbrar a noção de isolamento do bebê não apenas do lado patológico, mas também como uma capacidade humana de estar absorto consigo mesmo. Ou seja, antes de ver o autismo como uma patologia mental ou uma doença neurobiológica, torna-se necessário recuperar a noção original do termo autismo, tal como descrito por Freud e Bleuler. Ao se fazer isso, pode-se entender melhor a natureza do fenômeno a ser observado, principalmente no bebê.

$\mathrm{Na}$ história da psiquiatria, o termo autismo tem um significado muito mais amplo e complexo, desde Freud, Jung e Bleuler, do que o reducionismo biológico realizado pela psiquiatria da infância. Levando-se em conta o pensamento original de Freud (1895) sobre os primeiros momentos da vida de um recém-nascido no capítulo sobre "A vivência da satisfação" - o princípio fundamental do processo primário do funcionamento psíquico seria o de buscar prazer e evitar o desprazer. O desprazer significa um aumento de tensão que nasce no organismo do bebê. Só se pode conseguir alívio do desprazer mediante uma ação específica, como através de seus gritos, que atraem a atenção de uma pessoa experiente e capaz de aplacar suas necessidades. Segundo Freud, "essa via de descarga adquire a importantíssima função secundária da comunicação, e o desamparo inicial dos seres humanos é a fonte primordial de todos os motivos morais" (p. 422).

A vivência original de satisfação é alucinada quando o estado de necessidade se reproduz. O Ego aprende a diferenciar, mediante o signo da realidade, a alucinação da percepção, pois a percepção é a única capaz de aplacar a necessidade. Ou seja, a vivência original de satisfação constitui o núcleo do conceito psicanalítico de "objeto", estando ainda latente a ambivalência dos afetos 


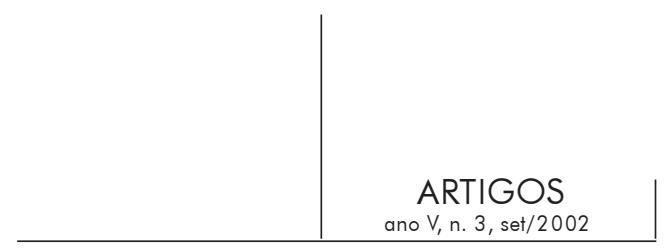

frente a este "objeto". Para o lactente, o primeiro objeto gratificador é ao mesmo tempo hostil e a única força auxiliar.

Em 1905, Freud publicou "Três ensaios sobre a teoria da sexualidade infantil" onde descreveu as fases do desenvolvimento da sexualidade da criança. Freud utilizou o termo auto-erotismo, introduzido por Ellis (1898), para definir a sexualidade infantil. O intuito de Freud era demonstrar que a pulsão existente em uma criança não é dirigida inicialmente para outras pessoas, pois a criança se satisfaz no próprio corpo. Freud demonstrou não existir um caminho préformado capaz de levar o sujeito a procurar o seu objeto de satisfação sexual. No início da vida, a criança encontra prazer em seu próprio corpo, no ato de sugar ou chupar que, para Freud, é o modelo do auto-erotismo.

O conceito de auto-erotismo foi retomado posteriormente por Jung e Bleuler para descrever a vida fantasiosa dos esquizofrênicos, com uma diferença: esses dois autores não concordaram com Freud sobre o papel da sexualidade na etiologia das doenças mentais. Em função da discordância, Bleuler inventou o termo autismo, que nada mais é do que o auto-erotismo de Freud sem Eros (Tafuri, 1985; Fédida, 1992; Atem, 1998; Berlinck, 1999). Dessa forma, Eros desapareceu na descrição psiquiátrica das Esquizofrenias. Note que de maneira semelhante, no caso do Autismo infantil precoce, Kanner desconsiderou o papel de Eros na nova doença descrita por ele. Em ambos os casos, parece ter havido um engano.

Na visão de Hanns (1966), o Eros em Freud deve ser compreendido a partir do verbete alemão Lust. No caso da sexualidade infantil, Freud o utilizou "na acepção de sensação prazerosa; a palavra (Lust) enfatiza a sensação extraída da atividade, visa a atividade e não o objeto. Designa aquilo que há de mais imediato e irredutível na sensação, quando esta brota no corpo, antes ainda da fruição plena do prazer e do gozo" (Hanns, 1996, p. 147). Freud também utilizou esse termo no sentido da "vontade", "vontade de fazer algo", uma vontade que brota (o brotar súbito de humor, as mudanças abruptas de uma criança...). Ainda, segundo Hanns, o Lust é um termo que enfatiza a sensação de ser afetado, estimulado ou sensibilizado corporalmente nas suas sensações. Ou seja, o prazer do Lust ao qual Freud se referiu em 1905 é diferente do gozo, do prazer sexual, que implica em uma fruição plena de certas sensações. O prazer do Lust na concepção de Freud é tratado como uma disposição, uma vontade, ou sensações que brotam no corpo do ser humano.

Freud descreveu a maneira como o bebê sente o prazer-Lust em seu próprio corpo desde o início da vida, ao se referir aos sentidos que podem estar ligados a uma pulsão/instinto (Trieb) associada à natureza animal, ou aos sentidos referentes a um anseio psíquico, espiritual. Entre esses dois sentidos, diferenciados pela sua essência e não pela intensidade, ocorre uma transição constante e que continua durante o desenvolvimento da criança, desde o seu nascimento. 


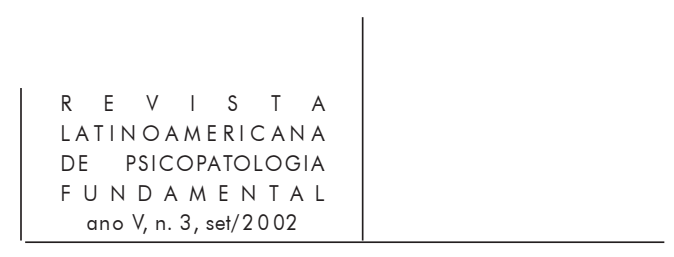

Para Freud, as pulsões auto-eróticas, no sentido do Lust, estão presentes desde o início da vida; e o bebê vive segundo as leis do princípio do prazer, caracterizado pela extrema labilidade das representações, pela mobilidade dos afetos e pela possibilidade de condensar e de deslocar as cargas afetivas de determinadas representações para outras.

Segundo Freud, o bebê alucina a satisfação de suas necessidades internas. A decepção ante a ausência da satisfação esperada motiva o abandono dessa tentativa de satisfação por meio de alucinações. Para substituir a alucinação, o aparelho psíquico tende a representar as circunstâncias reais do mundo exterior, e tende a realizar modificações nesse mundo. $\mathrm{O}$ que leva o bebê a fazer a ligação libidinal com o mundo externo é a percepção de que a alucinação não aplaca por completo a necessidade de sobrevivência. O lactente aprende a distinguir entre o seio alucinado e o seio real, este o único capaz de fazer cessar a sua necessidade. Essa distinção seria o protótipo de todas as distinções posteriores; e a pressão da necessidade obrigaria o bebê a introduzir no funcionamento psíquico o princípio da realidade. Por meio deste princípio, pode-se diferenciar o recordado/alucinado do percebido, de onde vem a instauração progressiva do processo secundário, dependente do princípio de realidade.

Posteriormente, em "Pulsões e destinos de pulsão", Freud (1915) demonstrou a existência de três polaridades que dominam a vida psíquica desde o início da vida: a do prazer/desprazer, a do sujeito/mundo e a da atividade/ passividade, sendo que as duas primeiras estão intimamente relacionadas. $\mathrm{Na}$ formação da psique, a distinção entre o si mesmo e o mundo externo esbarra em dois processos complementares: a introjeção e a projeção. No início da vida, o ser humano não distingue o interno do externo; o ego encontra-se investido por pulsões que, em grande parte, podem satisfazer-se a si mesmas: é a etapa do autoerotismo. Assim, estabelece-se a primeira divisão entre o prazer e o desprazer, coincidindo o ego com o prazer, enquanto tudo o que causa desprazer é identificado como sendo o mundo exterior. Como ainda não existe a percepção do corpo próprio, o bebê não diferencia o seu corpo do da mãe.

A necessidade de sobrevivência obriga o bebê a representar, para si mesmo, não apenas o agradável, mas também o desagradável, isto é, os estímulos geradores de tensão que provêm do mundo exterior para o corpo. A introdução do princípio da realidade é decisiva para a vida posterior do indivíduo, estando na origem de funções psíquicas essenciais, como a consciência, a atenção, a memória e o discernimento, a partir dos quais se formará o pensamento. Aquilo que está no exterior é que satisfará as necessidades de sobrevivência do bebê; assim, as pulsões sexuais se dissociam das pulsões de autoconservação.

Para Freud, o bebê pode tomar por objeto inicial as partes do próprio corpo (zonas erógenas) e ignorar, por um certo tempo, as determinações do real. 


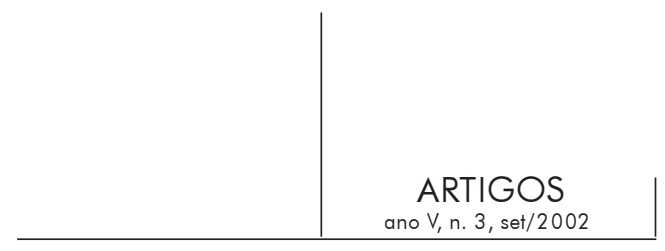

Posteriormente, pode manter frente a elas uma certa independência. Ou seja, criar a área da ilusão. Em particular, a fantasia, regida essencialmente pelo princípio do prazer, conserva um enlace especial com as pulsões sexuais, enquanto as pulsões do ego se encontram associadas à consciência e, portanto, ao princípio da realidade.

Segundo Winnicott (1968) a capacidade humana de criar uma área de ilusão é de fundamental importância para a possibilidade posterior de "estar absorto consigo mesmo", acompanhado de fantasias e idéias criativas: “... o bebê criou o seio, mas não poderia tê-lo feito se a mãe não chegasse a ele com o seio exatamente naquele momento". A imagem do seio criada pelo bebé é importante para ele na medida em que significa a presença do ser, a presença do outro. Nesse sentido, Winnicott argumenta: “... embora muitos tipos de experiência levem à formação da capacidade de ficar só, há um que é básico, e sem o qual a capacidade de ficar só não surge; essa experiência é a de ficar só, como lactente ou criança pequena, na presença da mãe. Assim, a base da capacidade de ficar só é paradoxal; é a capacidade de ficar só quando mais alguém está presente" (1958, p. 32). Por isso, o bebê adquire a capacidade de "estar absorto consigo mesmo" na presença da mãe, "ainda que representada por um momento, por um berço ou um carrinho de bebê, ou pela atmosfera geral do ambiente próximo" (p. 33).

Para Winnicott, self e criatividade estão indissoluvelmente ligados. A criança cria um campo singular de representações na medida em que a mãe, ou a pessoa que cuida dela, oferece-lhe presença viva. Uma articulação contínua entre o sujeito e o outro. Nesse sentido, a organização das pulsões auto-eróticas é essencial para que o bebê possa "interessar-se às comunicações das pessoas" e ao mesmo tempo criar o estado de ilusão, ou seja, "estar absorto consigo mesmo" acompanhado por fantasias e idéias criativas.

Em síntese, o isolamento autista pode ser compreendido pelo viés do conceito de auto-erotismo (autoerotismus), composto de autos e Eros. Implica em distinguir entre o que pode ser concebido como autos e o que se reflete apenas pelo selbst ou autoconservação. O cuidar de si mesma, autos, leva a criança a representar a si própria pelo pronome eu (uma das falhas básicas da criança autista é a impossibilidade de referir-se a si mesma pelo pronome pessoal "eu", ela tende a usar o pronome da terceira pessoa do singular "ele", ou o nome próprio). Assim também são as capacidades humanas de "estar só na presença da mãe" e "estar absorto consigo mesmo" a serem constituídas pelo bebê desde o início da vida, para que ele possa cuidar de si mesmo.

Em Kanner, a subtração de Eros do termo autismo significou a perda desse referencial constitutivo do ser - a criação da área de ilusão. A Classificação Diagnóstica: 0 a 3 é um exemplo da perpetuação desse pensamento reducionista no qual o isolamento do bebê é descrito como autista quando comparado com a 


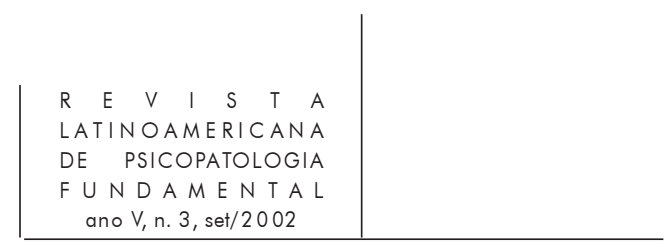

sintomatologia da criança autista. O isolamento do bebê pode ser observado com outros olhos desde que o saber médico sobre os índices precoces patológicos não seja visto em relação linear causal com a síndrome do Autismo infantil precoce.

A observação de sinais de isolamento no bebê pode e deve ser alargada desde que se considere a noção originária do termo autismo. E esses sinais de isolamento do bebê podem, além do mais, ser analisados para além da visão psicopatológica do termo autismo, tal como previsto na literatura psicanalítica, a partir do auto-erotismo, lust.

\section{Referências}

Ajuriaguerra, J. Manuel de psychiatrie de l'enfant. Paris: Masson, 1970.

American Psyquiatric Association: Manual de Diagnóstico e Estatística de Distúrbios Mentais. DSM-III-R. São Paulo: Manole, 1989.

American Psyquiatric Association: Manual de Diagnóstico e Estatística de Distúrbios Mentais. DSM-IV. Option Book, Washington: Work in progress-APA, 1991.

Aтем, L. M. Autismo e defesa primária: questões sobre o sujeito e a transferência.

Revista Latinoamericana de Psicopatologia Fundamental, v. 1, n. 1, p. 77-85, mar./1998.

Bender, L. Childhood schizophrenia. Nerv. Child. 1, 138-40, 1942.

Psychopathic conduct disorder in children. In: Lindner, R.M. A Handbook of Correctional Psychiatry. New York: Philosophical Library, 1947.

BerLinCK, M.T. Autismo, paradigma do aparelho psíquico. Estilos da Clínica. Instituto de Psicologia - USP, v. 4, n. 7, p. 30-42, 1999.

Berquez, G. L'autisme infantile. Introduction à une clinique relationonnelle selon Kanner. Paris: PUF, 1983

O autismo infantil e Kanner. In: Lebovici, S.; Mazet, P. Autismo e psicoses da criança. Porto Alegre: Artes Médicas, 1991.

Bleuler, E. Autistic thinking. Am. J. of Insanity, 69, 1913.

Dementia praecox oder grupp der schizophrenien, tradução resumida para a língua francesa por Henri Ey. Anaclitis, 1964.

L'invention de l'autisme. Analytica, Cahiers de recherche du Champ freudien. Traduzido do alemão por Yves Kaufmant. Paris: Navarin, 1988.

CiD-10: Classificação de Transtornos Mentais e de Comportamento. Porto Alegre: Artes Médicas, 1993.

FÉDIDA, P. (1990) Auto-erotismo e autismo; condições de eficácia de um paradigma em psicopatologia. Trad. Martha Gambini e Claudia Berliner. In: Nome, figura e memória. A linguagem na situação psicanalítica. São Paulo: Escuta, 1992, p. $149-70$. 


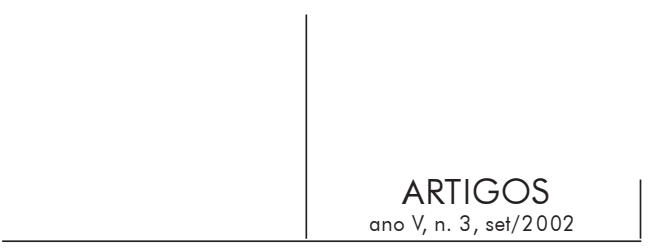

Freud, S. (1895). Projeto para uma psicologia científica. In: E.S.B. Rio de Janeiro: Imago, 1980, p. 381-472. v. 1.

(1905). Três ensaios sobre a teoria da sexualidade. In: E.S.B. Op. cit., p. 5217. v. 7.

(1910). As perspectivas futuras da terapêutica psicanalítica. In: E.S.B. Op. cit., p. 127-40. v. 11. 14.

(1914). Sobre o narcisismo: uma introdução. In: E.S.B. Op. cit., p. 89-121. v.

(1915). Artigos sobre metapsicologia. In: E.S.B. Op. cit., p. 123-252. v. 14.

(1923). O ego e o id. In: E.S.B. Op. cit., p. 23-90. v. 19.

Hanns, L. (1996). Dicionário comentado do alemão de Freud. Rio de Janeiro: Imago, 1996.

KAnNer, L. Autistic disturbances of affective contact. Nervous Child, v. 2, n. 3, p. 217-50, 1942-43.

Early infantile autism. Journal of Pediatrics, 25, p. 211-217, 1944.

Irrelevant and metaphorical language in early infantile autism. American Journal of Psychiatry, 103, 242-45, 1946.

Problems of nosology and psychodynamics in early infantile autism. American Journal Orthopsychiatry, v. 19, p. 416-26, 1949.

The conception of woles and parts in early infantile autism. American Jounal Psychiatry, v. 108, p. 23-6, 1951.

To what extent is early infantile autism determined by constitutional adequacies? In: HoOKer, D.; HARE, C.C. (Eds.). Genetics and the inheritance of integrated neurological psychiatric patterns. Baltimore, williams e Wilkins, 1954. Revisado posteriormente em Childhood Psychosis, p. 69-75, 1973.

The specificity of early infantile autism. Acta Paedopsychiatry, v. 25, n. 1-2.

p. 108-13, 1958.

Infantile autisme and the schizophrenias. Behavorial Science, v. 10, n. 4, p. 412-20, 1965.

The thirty-third Maudsley lecture. Journal of Mental Science, v. 105, p. 58193, 1959.

Early infantile autism revisited. Psychiatry Digest, v. 29, p. 17-28, 1968.

Revisto em Childhood psychosis, 135-41, 1973.

Follow-up study of eleven autistic children originally reported in 1943. Journal

of Autism and Childhood Schizophrenia, v. 1, p. 119-45, 1971.

Childhood psychosis: initial studies and new insights. Washington: H. Winston

\& sons, 1973.

(1941) En defensa de las madres. Buenos Aires: Paidós, 1974.

; Eisenberg, L. Notes on the follow-up studies of autistic children. In: HocH,

P.H.; Zubin, I. eds. Psychopathology of Childhood. New York: Grune \& Stratton, 1955, p. 227-39. 


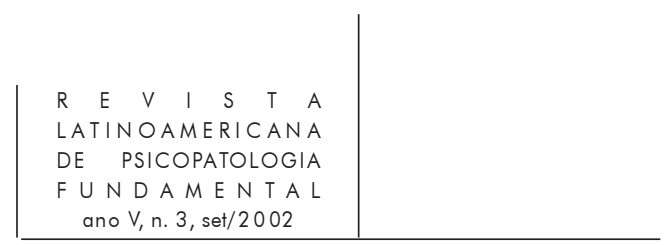

; __ Early infantile autism, 1943-1955. American Journal Orthopsychiatry, v. 26, n. 3 , p. 556-66, 1956.

;

Early infantile autism. Pediatric Clinic of North America, 711-30, 1958

Kanner, L.; Rodriguez, A.; Ashenden, B. How far can autistic children in matters of social adaptation? Journal of Autism and Childhood Schizophrenia, v. 2, n. 1, p. 9-33, 1972.

National Center For Clinical Infant Program. Classificação diagnóstica: 0 a 3 classificação diagnóstica de saúde mental e transtornos do desenvolvimento do bebê e da criança pequena. Trad. Maria Cristina Monteiro. Porto Alegre: Artes Médicas, 1997.

TAFURI, M.I. Autismo infantil precoce e nome próprio: um estudo exploratório, teórico clínico, acerca do sistema de nominação. Dissertação (Mestrado). Brasília, UnB, Instituto de Psicologia, 1990.

Autismo infantil precoce. Insight, n. 16, fev./1992.

O início do tratamento psicanalítico com crianças autistas: transformação da técnica psicanalítica? Revista Latinoamericana de Psicopatologia Fundamental, v. 3, n. 4, p. 122-45, dez./2000.

Winnicott, D.W. (1948). Primary introduction to external reality: the early stages. In: Thinking about children. London: Karnac Books, 1966.

(1958). A capacidade para estar só. In: O ambiente e os processos de maturação. Estudos sobre a teoria do desenvolvimento emocional. Trad. Irineo Constantino Schuch Ortiz. Porto Alegre: Artes Médicas, p. 31-7, 1982.

(1963). Da dependência à independência no desenvolvimento do indivíduo.

In: $O$ ambiente e os processos de maturação. Op. cit., p. 79-87.

(1957) Sobre a contribuição da observação direta da criança para a psicanálise.

In: $O$ ambiente e os processos de maturação. Op. cit., p. 101-5.

(1968). As comunicações entre o bebê e a mãe e o bebê, comparadas e contrastadas. In: Joffe, G. D. (org.). O que é psicanálise. Trad. Rebeca Schwartz. Rio de Janeiro: Imago, 1972.

(1969). A experiência mãe-bebê de mutualidade. In: Explorações em psicanálise. Trad. José Octavio de Aguiar Abreu. Porto Alegre: Artes Médicas, 1994.

(1971). O brincar e a realidade. Trad. José Octavio de Aguiar Abreu. Rio de Janeiro: Imago, 1975.

(1987). O gesto espontâneo. Trad. Luís Carlos Borges. São Paulo: Martins Fontes, 1990.

(1978). D.W.W.: uma reflexão. In: Explorações psicanalíticas. Op. cit. 


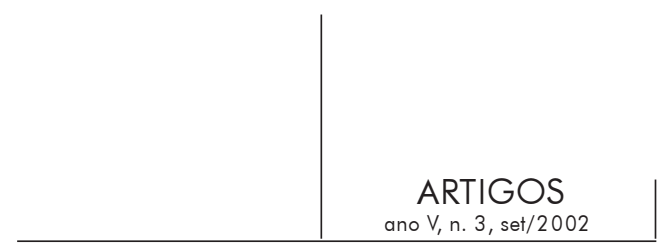

Resumos

El tratamiento preventivo de los trastornos precoces con risco de evolución autista es discutido en este texto como una acción paradojal desde el punto de vista psicoanalítico. La prevención implica en la perpetuación del pensamiento psiquiátrico kraepeliano sobre la evolución necesaria de un grupo de síntomas de una enfermedad dada. Al mismo tiempo se da énfasis a la necesidad del tratamiento precoz de bebes con aislamiento patológico.

Palabras llave: Autismo, autoerotismo, prevención, psicopatología, páthos

Le traitement préventif des troubles précoces des risques d'une évolution autistique est discuté dans ce texte comme conduisant à une action paradoxale du point de vue psychanalytique. La prévention impliquerait la continuitée de la pensée psychiatrique de Kraepelin, qui prévoit l'évolution obligatoire d'un groupe de symptômes d'une maladie donnée. En même temps ce travail fait bien ressortir le besoin de traitement du bébé.

Mots clés: Autisme, auto-erotisme, prévention, psychopathologie, páthos

This paper discusses the preventive treatment of early development in children with risk of autistic evolution as paradoxical from the psychoanalytic point of view. Prevention implies perpetuation of Kraepelin's psychiatric position on the inevitable evolution of the group of symptoms of a given disease. At the same time, the need for babies' early treatment is emphasized, especially for those with pathological isolation.

Key words: Autism, auto-erotism, prevention, psychopathology, páthos

Versão inicial recebida em maio de 2002

Versão revisada recebida em agosto de 2002 